\title{
Using virtual reality for dynamic learning: an extended technology acceptance model
}

\author{
Stephanie G. Fussell ${ }^{1}$ (D) . Dothang Truong ${ }^{2}$
}

Received: 28 August 2020 / Accepted: 22 June 2021 / Published online: 10 July 2021

(c) The Author(s), under exclusive licence to Springer-Verlag London Ltd., part of Springer Nature 2021

\begin{abstract}
Virtual reality (VR) is being researched and incorporated into curricula and training programs to expand educational opportunities and enhance learning across many fields. Although researchers are exploring the learning affordances associated with VR, research surrounding students' perceptions of the technology, and intentions to use it for training has been neglected. The goal of this research was to determine the factors that influence students' intention to use VR in a dynamic learning environment. An extended Technology Acceptance Model (TAM) was developed that incorporates factors related to education and the use of VR technology in training environments. Confirmatory factor analysis (CFA) and structural equation modeling (SEM) processes were employed. Nine of 14 hypotheses in the original model were supported, and eight of the nine predictor factors of the model were determined to directly or indirectly impact behavioral intention (BI). The original TAM factors had the strongest relationships. Relationships between factors particularly relevant to VR technology and learning were also supported. The results of this study may guide other educators interested in incorporating VR into a dynamic learning environment.
\end{abstract}

Keywords Virtual reality · Dynamic learning · Aviation education · Education technology · Technology acceptance model · Student perception

\section{Introduction}

Technology is increasingly being used in education and training for a variety of fields and presents a wide range of options for educators (Suh and Prophet 2018). The late twentieth century saw technology rise in popularity for the educational domain which continued into the twenty-first century, including mobile learning (m-learning) on smartphones, augmented reality by way of a tablet, and fully immersive experiences in simulated environments such as virtual reality (VR) (Sitzmann 2011). VR technologies are being incorporated into educational programs, especially in dynamic learning environments, to train students and novices on complex scenarios in a safe and controlled environment, and

Stephanie G. Fussell

Sfussel2@kent.edu

1 Graduate Studies, College of Aeronautics and Engineering, Kent State University, Kent, OH, USA

2 School of Graduate Studies, College of Aviation, Embry-Riddle Aeronautical University, Daytona Beach, FL, USA practice iterative procedures without impacting the wear and tear of expensive simulators. Using VR technology for training purposes can reduce error rate and enhance the learning experience while increasing time savings and decreasing costs (Smith and Salmon 2017). There is anecdotal and empirical evidence that simulation technology can enhance knowledge, psychomotor skills, and motivation (Sitzmann 2011). VR can also enhance engagement, explore material in a new way, and facilitate interactive learning (Lindgren et al. 2016; Makransky et al. 2017). VR offers educators and trainers a robust modality that can diversify training from on-site, physical simulators and machinery to fully virtual environments, enabling training from home or off-site locations with smaller physical footprints and maintenance considerations. VR also allows students to practice skills on their own time and at their own pace. Such off-site training can easily comply with COVID-19 precautions of the educational institutions and reduce the use of physical equipment among many students, adding an additional layer of social distancing while still maintaining a curriculum or training schedule. 
However, the benefits associated with using VR in educational environments will not be realized if students do not use them or utilize other training devices or simulators. The specific factors that drive students to use VR in a dynamic learning environment have not been widely studied (Chang et al. 2018; Lee et al. 2018b; Lin and Peh 2019; Sagnier et al. 2020). The technology acceptance model (TAM; Davis et al. 1989) may be used to understand how users come to accept and use a given technology, including in educational environments (King and $\mathrm{He} 2006$ ). The TAM and its various extensions have been utilized to understand user perception of VR in different contexts, yet VR use in dynamic learning environments has received little attention (Huang 2020; Mahalil et al. 2020; Manis and Choi 2018; Shen et al. 2018). The lack of literature surrounding the use of VR in dynamic learning environments is a concern, as VR can also negatively impact the learning process (Makransky et al. 2017; Maraj et al. 2015; Polcar and Horejsi 2015).

The purpose of this study was to determine the factors influencing students' intention to use VR in a dynamic learning environment. The intent was to fill a gap in the literature related to using VR in dynamic learning environments by extending the TAM to include factors that are relevant to dynamic learning as well as VR. A measurement model and survey instrument were created and tested on a refined study population of students receiving flight training at Pilot Schools in the U.S. (Pilot Schools 14 CFR $\$ 141$ 2020). This population was chosen as learning and training is active, relies on student progression, and students must rapidly adapt based on incoming information. Further, the aviation industry has demonstrated itself as a leader in using immersive simulation training devices for dynamic learning in a variety of contexts, yet has not embraced VR technology as a training alternative (Lewis and Livingston 2018; Macchiarella et al. 2005; Macchiarella and Meigs 2008; Palla et al. 2018). It must be said that although flight training occurs in a dynamic learning environment, the results may not generalize to other dynamic learning environments; it is simply one example. VR was presented as a system to enhance training on procedures and maneuvers in a flight training device. The research was accomplished by creating an extended TAM based on the foundation theories presented by Davis et al. (1989). This model encompassed factors that are relevant for assessing VR technology in a dynamic learning environment. Validated factors from TAM and Ajzen's (1991) theory of planned behavior (TPB) extended models were also adapted to focus on training utilizing VR technology. Although the factors have been validated in the literature in a variety of research contexts, the measurement model was designed to identify the relationships among the factors when users are presented with VR for learning in an educational environment. The factors are performance expectancy (PEXP), perceived health risk
(PHR) in using VR for training, regulatory uncertainty (RU) surrounding the use of VR in training, and self-efficacy (SE).

This model may explain the students' acceptance of VR in a dynamic learning environment as well as their intent to use the technology. Before VR is incorporated into an educational program, educators and developers must understand the factors that motivate a student to use VR for learning purposes to encourage user acceptance and intention. The study is discerned from others by nature of the research context and technology being studied (i.e., VR for dynamic learning) as well as the relationship among the factors. Those endeavoring to efficiently and effectively incorporate VR into a dynamic learning environment will find the results to be of interest. The study is especially relevant as institutions consider virtual learning options that meet training requirements while also enforcing safety precautions due to the ongoing COVID-19 pandemic.

This study investigated the following research questions:

(1) What factors influence students' intentions to use VR technology for training?

(2) How do these factors impact students' intentions to use VR technology for training?

(3) To what extent do these factors influence students' intentions to use VR technology for training?

This paper is organized as follows. First, background information, the research model, and the factors of the extended TAM are presented. The methodology of the study is then described, followed by the results of the study. Finally, the results are discussed, the research questions are addressed, conclusions are drawn, and implications and directions for future research are presented.

\section{Background and research model}

\subsection{Virtual reality in dynamic learning environments}

VR is a 3-dimensional (3D) digital environment generated to create a fully immersive, realistic environment (Jerald 2016; Virtual Reality Society 2017). This technology is being adopted in a variety of educational environments as a training device. VR in education and training provides the ability to train and practice while encouraging active learning, intuitive decision making, and engagement with a task (Jerald 2016). Numerous research studies demonstrate the benefits of using VR in dynamic learning environments. A study by Lin and Yeh (2019) found that spatial training and learning in VR can positively impact PEU, PU, intention, and perceived playfulness; their findings indicate that the interactive quality associated with learning in VR can 
positively impact the student's desire to use the technology. Lindgren et al. (2016) found that students who learned using whole-body activity in the immersive environment had significantly higher learning gains, higher engagement with the subject, and a more positive attitude toward science when compared to students using a computer simulation. Makransky et al. (2017) discovered that students reported a higher presence in a VR learning environment; however, results indicated they learned less than students using a computer simulation and had a significantly higher cognitive workload. Smith and Salmon (2017) explored how different levels of immersive instruction translated to assembling a complex mechanism. Although there was no difference in time nor accuracy between the participant groups when tested on assembly in the real world, over $85 \%$ of the participants indicated that VR training with a 3D walkthrough and instructions were preferred, particularly when the assembly procedure was very involved or complex.

There are many benefits to using immersive simulation technology, such as VR, in dynamic learning environments. Using active learning for complex and dynamic concepts may positively impact learning and understanding (Lindgren et al. 2016). Learning can be expanded outside of the classroom, or in the case of aviation the cockpit, to further training using VR. Repeating tasks in a VR environment can positively impact cognition and memory, visual-spatial skills, psychomotor skills, and emotional responses (Jensen and Konradsen 2018). However, attaining these affordances necessitates designing a safe, effective, and usable VR learning environment wherein the user may attain goals in a motivating and cost-efficient environment (Eastgate et al. 2015). Frustration may occur if the student is unfamiliar with the technology, negatively impacting performance while using VR (Maraj et al. 2015). As VR is incorporated into the classroom, educators and trainers must ensure learning outcomes are met while providing cognitive experiences for students associated with using VR for training.

\subsection{Immersive simulation technologies in aviation training}

Aviation training occurs in dynamic learning environments. Because the context of this study focused on flight training at Pilot Schools as a representation of a dynamic learning environment, it is important to understand the use of immersive simulation training devices for flight training. Researchers and educators have long advocated the use of flight simulation training devices, or simulators, as high-fidelity, lowcost options with numerous learning benefits for training in aviation. Simulators have different levels of fidelity and immersion yet provide realistic training scenarios to enhance procedural memory and performance while decreasing costs associated with flight training (Macchiarella et al. 2008).
Research on the use of different levels of simulators in terms of fidelity and realism has regularly shown that flight training in a simulated environment is both efficient and effective. Numerous studies have demonstrated that training with computer-based aviation training devices is effective for learning and practicing procedures and maneuvers, especially when related to instrument flight tasks (Leland et al. 2009; Reweti et al. 2017; Rogers et al. 2010; Taylor et al. 2004). Students who received flight training in a high-fidelity flight training device required fewer iterations to achieve flight standards, generally demonstrated positive transfer of training from the device to the airplane, realized cost savings, and often outperformed others who did not use a flight training device (Cardullo et al. 2011; Leland et al. 2009; Koglbauer 2016; Macchiarella et al. 2008; McLean et al. 2016; Taylor et al. 2005). Full flight simulators have been used primarily to evaluate transfer of training when motion is introduced into the training environment; empirical evidence suggests that motion does not affect the transfer of training but that using a full flight simulator provides effective training in general (Bürki-Cohen et al. 2007; Landman et al. 2018; Pool et al. 2016; Zaal et al. 2015). Overall, simulators have been used efficiently and effectively to train pilots at all experience levels.

Apart from full flight simulators, most simulators lack the full immersion associated with VR. VR is the logical next technology to conduct transfer of training research, yet a review of the extant literature revealed that VR is relatively unused in flight training programs. One exception is the use of VR programs for military pilots; even then, research is limited to the development, usability testing, and pilot tests of new systems. The military has been exploring the use of low-cost, high-fidelity flight simulators using commercial off-the-shelf hardware and software. Palla et al. (2018) created an immersive part-task trainer for military pilots to receive checklist instruction in a VR cockpit. Participants reported that the trainer was easy to use and would benefit the training program by increasing both confidence and proficiency. Lewis and Livingston (2018) also created a testbed to study the incorporation of VRs into a pilot training program called Pilot Training Next. Data collected thus far have demonstrated that the Pilot Training Next program is an affordable option that can leverage VR and other technologies to enhance military pilot training. VR for the training of pilots at Pilot Schools is still being investigated as an alternative for simulator training. Lawrynczyk (2018) found that flight training in a simulator or VR resulted in similar performance results or better in the VR group, indicating that VR for flight training may be a viable alternative. A study comparing the academic performance of student pilots who learned maneuvers in VR or using computerbased 2D simulation indicated that training in the immersive VR environment did not hinder mastery; additionally, both 
groups indicated that simulation was the preferred medium for learning flight training maneuvers as opposed to reading materials, videos, and face-to-face instruction (Hight and Fussell 2021).

A review of the literature reveals that research surrounding student's attitude toward and intent to use technology for flight training has received little attention using objective measures. Lawrynczyk (2018) found that user experience and performance measures were comparable between simulator and VR flight training groups, but those who trained in VR experienced higher cognitive load. Researchers often collect subjective data regarding how students perceive a given technology will benefit flight training (Bürki-Cohen \& Go 2005; Bürki-Cohen et al. 2007; Fussell et al. 2019; Fussell and Hight 2021). However, the studied simulation technologies were generally simulators as opposed to VR.

\subsection{Foundation theories}

\subsubsection{Technology acceptance model}

The perception of technologies by individuals may impact how they use them in different environments. Davis et al. (1989) developed the TAM "to explain the potential user's behavioral intention to use a technological innovation" (King and He 2006, p. 740). King and He (2006) noted that the TAM is a widely used model in part due to its "understandability and simplicity" (p. 740). The applicability of the model has led to its use in a variety of domains for a variety of technologies. Davis' (1989) original variables, perceived ease of use (PEU) and perceived usefulness (PU), have been demonstrated to strongly correlate with user's attitude toward using (ATU) a technology and behavioral intention (BI) to use a given technology. These four factors have formed the foundation of many studies investigating new technology. In his 1989 work, Davis described that PEU is supported by Bandura's research of self-efficacy (SE), or personal belief (confidence) in one's ability to accomplish a given behavior (Bandura 1991). Confidence derived from SE directly impacts a person's thoughts, actions, and motivation.

As the TAM has been extended with new factors and tested in a variety of fields, the reliability and validity of the model have been demonstrated, as has the adaptability of the model. In education, the TAM has been utilized to assess behavioral intent to use e-learning tools (Gong et al. 2004; Park 2009). The TAM has not been widely used to explain the intention to use technology in an aviation environment, although the applications where it has been utilized are diverse (Lu et al. 2009; Myers and Truong 2020; Richardson et al. 2019). The use of the TAM for VR has received little attention as the technology is quite new, but researchers are starting to explore the technology in different contexts (Chang et al. 2018; Manis and Choi 2018; Shen et al. 2018).
The constructs of perceived enjoyment (PENJ) and performance expectancy (PEXP) have been included in studies related to $\mathrm{BI}$ to use innovative technology in educational and consumer contexts, expanding the scope of the TAM (Abdullah and Ward 2016; Chang et al. 2018; Lewis et al. 2013; Makransky and Lilleholt 2018; Manis and Choi 2018; Shen et al. 2018). The intersection of VR, aviation training, and the TAM is virtually non-existent outside of the work of Wang et al. (2016), which utilized the original factors of the model, and Sagnier et al. (2020). Sagnier et al. (2020) assessed user acceptance of VR for an aeronautical assembly task through the use of an extended TAM and included factors relevant to using VR in a training task (including cybersickness, presence, and hedonic quality stimulation). They found that intention is positively influenced by PU, which in turn is impacted by hedonic quality stimulation and personal innovativeness are predictors of perceived usefulness. As these technologies become more ubiquitous in training environments, the constructs must be reconsidered through the lens of the virtual environment for learning in dynamic environments.

\subsubsection{Theory of planned behavior}

Ajzen proposed the TPB as a derivative from the theory of reasoned action (TRA) in 1991 to study, predict, and explain human behavior with an emphasis on intent to perform anticipated behavior. Ajzen (1991) added the factor of perceived behavioral control (PBC) as a predictor of intention to expand the TRA. PBC is how easy the user believes it will be to use the given technology or behavior and is dependent upon opportunity, available resources, and user familiarity (Ajzen 1991).

The TPB has been used in the aviation environment to assess consumer behavior (Lee et al. 2018a; Pan and Truong 2018) and in the learning environment to assess perceptions toward online learning (Cheon et al. 2012). A review of the literature reveals that the TPB has not been used in the context of immersive simulation technology, let alone VR specifically, for education or training purposes, nor in the aviation education environment. The underlying constructs may be adapted for intent to use specific technologies for aviation training, and constructs of the TPB may be adapted and incorporated into extended TAM models.

\section{Research model}

The original TAM (Davis 1989) has been utilized for identifying factors that impact user acceptance of a technology in various technologies and environments, demonstrating that it is a valid and robust model (King \& He 2006). The extant literature indicates that an appropriate approach for 
researching student acceptance of VR technology in an educational environment is expanding the original TAM to include factors relevant to VR and/or education, as appropriate (Chang et al. 2018; Davis 1989; Lee et al. 2018a, b; Makransky \& Lilleholt 2018; Manis \& Choi 2018; Shen et al. 2018). Researchers have also extended the TAM to include new factors that better explain user acceptance in specific contexts. In educational and training environments, there are numerous examples of models that incorporate factors that are directly relevant to the environment or technology.

The model for the study was an extended TAM that incorporated constructs from TPB and previously validated extensions of the TAM. The constructs are directly related to dynamic learning environments and the use of VR technology for training. Table 7 in the appendix defines the 10 factors (constructs), provides the associated measurement items, and details the sources of the constructs and measurement items. All hypotheses between the factors were derived from previously validated relationships utilizing TAM, TPB, or an extension or combination thereof, although the factors have been combined in a new way for the dynamic learning environment and VR technology. The operational definitions of the factors are written for the context of the population the data was collected from. The theoretical framework in Fig. 1 highlights the relationships between the predictor variables and intention as opposed to actual behavior.

The relationship between PEU and PU stems from Davis (1989). It was expected that an increase in perceived ease of use would increase the ease of using VR technology for training, thus increasing performance. This concept has been validated in numerous other studies across a variety of domains and technologies (Gong et al. 2004; Lu et al. 2009; Manis and Choi 2018). As a necessary part of the TAM, the first hypothesis was "PEU of use positively influences PU."

PEU was also hypothesized to positively and directly influence ATU. A user may expect that using VR for training will not require extraneous effort and no more so than other immersive technology that has been used for training purposes (in the context of this study, a flight training device). If the technology is easily mastered, the user will be more inclined to use it. Davis (1989) first demonstrated this relationship in the original TAM, and it has been subsequently validated (Cheung and Vogel 2013; Manis \& Choi 2018). The second hypothesis was "PEU positively influences ATU."

The third hypothesis supports a relationship validated in Davis' (1989) original TAM and subsequent studies using the TAM and its variants (Cheung and Vogel 2013; Esteban-Millat et al. 2018). Using VR technology for

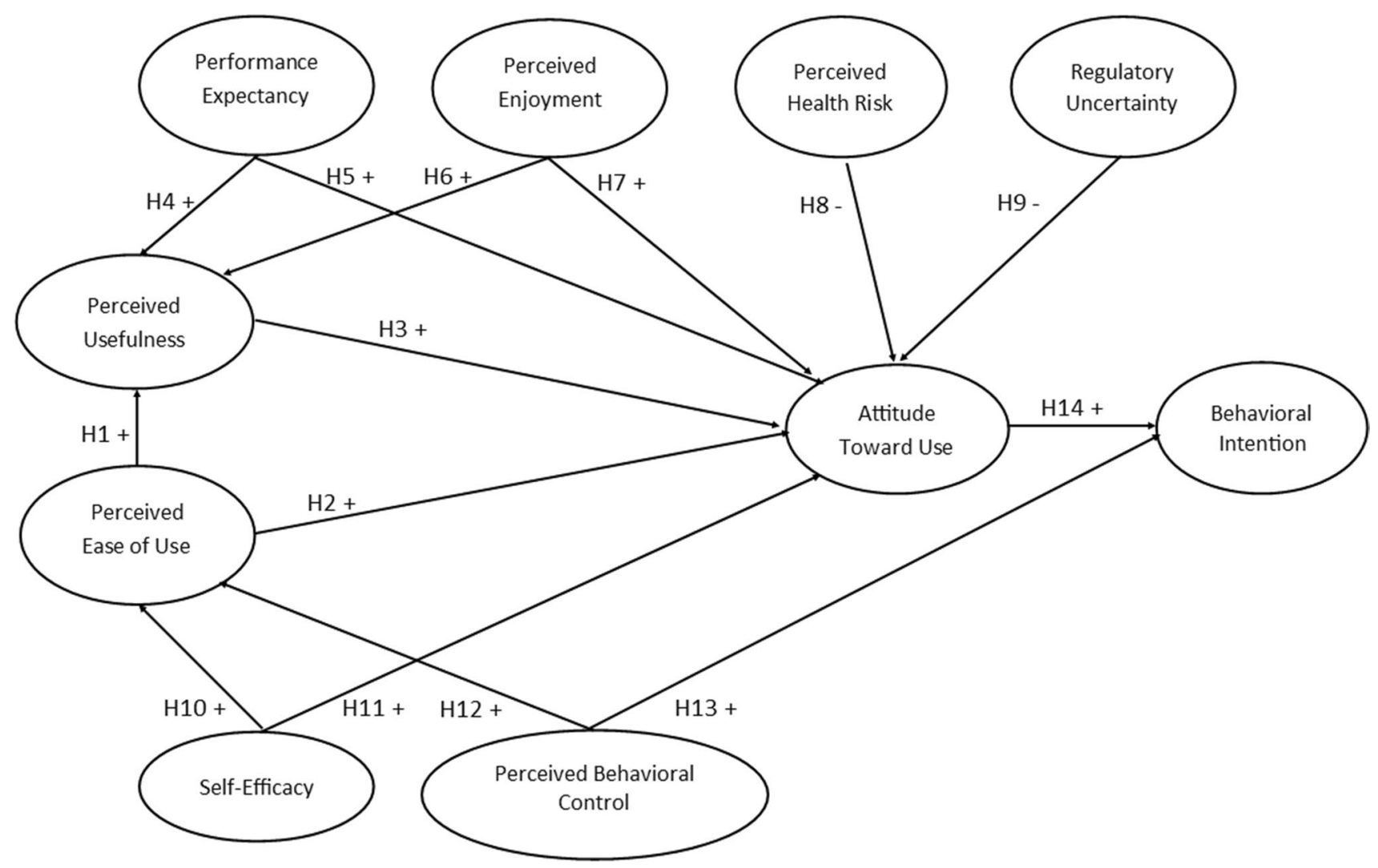

Fig. 1 Research theoretical framework and hypotheses 
training offers benefits that may enhance the learning process and may not be found in other technologies, thereby positively impacting attitude toward using the technology. The hypothesis was "PU positively influences ATU."

A relatively new construct, PEXP was used in a variant of the TAM (Lewis et al. 2013; Shen et al. 2018). PEXP relates to the belief that VR technology will improve performance as compared to another training device (e.g., a flight training device). The factor has been associated with $\mathrm{BI}$ and actual use. It was theorized that as the user's belief that using VR technology for training will improve performance, so too will the user's belief that VR is a useful tool for training. Both constructs measure the performance value of the technology. Thus, the fourth hypothesis is a new relationship: "PEXP positively influences PU."

The fifth hypothesis depicts the relationship between PEXP and ATU. As the user's expectancy increases in a favorable manner, it was theorized that attitude to use VR for training would also increase. The construct has been adopted from the studies that did not consider the ATU construct but actual use behavior (Lewis et al. 2013; Shen et al. 2018). The hypothesis was "PEXP positively influences ATU."

PENJ is another relatively new construct incorporated by Abdullah and Ward (2016) in the General Extended Technology Acceptance Model for E-Learning (GETAMEL). Enjoyment is an intrinsic motivation and, in this context, describes the extent to which the user will appreciate the experience of technology in its own right, regardless of performance expectations or results (Abdullah and Ward 2016). Learners who believe that using a given technology is enjoyable are also more likely to believe that the technology is useful and positively affects learning. The positive relationship between PENJ and PU has been supported (Abdullah et al. 2016; Chang et al. 2018), and the sixth hypothesized relationship was "PENJ positively influences PU."

Manis and Choi (2018) are among the only researchers to examine the relationship between PENJ and ATU of VR technology. They found that consumer perception of enjoyment was a key belief variable impacting motivation to use VR hardware, thereby influencing behavioral intent. Individual enjoyment of VR for training may affect a student's attitude to use VR in training. The seventh hypothesis was "PENJ positively influences ATU."

Increased perception of health risk of using VR for training may negatively impact acceptance and attitude toward using the technology. In the VE, users may experience health concerns due to simulator sickness. Those who have little to no experience with VR may also be less inclined to use the technology for training than those with experience.
Perceived risk, in general, has been shown to negatively impact ATU and BI (Lu et al. 2009; Myers and Truong 2020). PHR has not been examined for education nor VR technology. Building upon these relationships, the eighth hypothesis was "PHR negatively influences ATU."

The uncertainty caused by the lack of regulations regarding the use of VR for training may also impact ATU and cause hesitation to use the technology. The factor has not received much research (Folkinshteyn and Lennon 2016; Yang et al. 2015). The ninth hypothesized relationship is unique to the model, "RU negatively influences ATU."

SE is a user's individual judgment of how well a course of action can be executed in a prospective situation. The students' belief in their abilities, as well as their confidence in using VR technology, may positively influence their belief that using VR for training will be easy. This construct has been validated (Gong et al. 2004; Park 2009). Thus, the tenth hypothesis was "SE positively influences PEU."

SE may also influence attitude toward using VR technology for training. Those students who are confident in their abilities and/or their ability to use VR technology may be more favorably inclined toward using VR. This, in turn, will impact intention. Notably, this relationship has had mixed results in the TAM. Gong et al. (2004) found that SE positively affects BI; Park (2009) found that although SE positively influenced BI to use e-learning, there was not a statistically significant relationship between attitude and SE. The eleventh relationship was hypothesized as "SE positively influences ATU."

The twelfth hypothesis analyzed PBC, which refers to the perceptions formed about the ease or difficulty of using VR for training. Students who perceive they have resources available to them may believe that VR will be easy to use for training. This relationship was validated in extended models ( $\mathrm{Lu}$ et al. 2009; Venkatesh 2000). The hypothesis was "PBC positively influences PEU."

As a component of Ajzen's (1991) original TPB model, PBC was theorized to have a direct relationship with BI. The construct has a strong influence on BI as it considers available cognitive and situational resources required to perform a behavior (Ajzen 1991; Lu et al. 2009). Students who believe they have the opportunity to successfully use VR for training may have a greater amount of PBC. The relationship has not been widely investigated beyond Lu et al. (2009). The thirteenth hypothesis was "PBC control positively influences BI."

The fourteenth hypothesis has been validated by numerous researchers (Cheung \& Vogel, 2018; Esteban-Millat et al. 2018; Park 2009). It was hypothesized that attitude toward using VR for training would directly and positively influence the BI to use VR for training. Thus, the final hypothesis was "ATU positively influences BI." 


\section{Methodology}

\subsection{Research design and sampling}

This study utilized a quantitative research method with a cross-sectional survey design. A confirmatory factor analysis (CFA) and structural equation modeling (SEM) approach were chosen to analyze the multiple and interrelated dependence relationships, explain the relationships, account for the measurement error of estimation, and examine unobserved conceptual relationships (Hair et al. 2010). The technique was appropriate as the study incorporated untested factors and tested the theoretical framework.

Flight students at Pilot Schools in the U.S. were chosen as the target population for the study. Using proportional quota sampling, the final sample included 33 invited Pilot Schools, allowing for a sampling pool of over 8000 flight students. Participants had to be at least 18 years of age, enrolled in the institution's flight training program, and have begun flight training. The total number of flight students was collected from the invited institutions to ensure participants were representative of the population and increase the generalizability of the results. A minimum sample size of 475 for an anticipated effect size of 0.2 , the desired power level of 0.8 , and a probability level of 0.05 were calculated using Soper's (2020) online SEM sample size calculator of Westland's (2010) formula.

\subsection{Data collection and instrument}

Points of contact from each invited institution sent an email to aviation students at their respective institutions. The email included the invitation to join the study, a link to the survey instrument on Google Forms, and the researcher's contact information. Students received an initial invitation from their point of contact to participate in early January 2020, and a reminder email in February before the study closed in March 2020. Responses were anonymous, and minimal personal data were collected beyond demographics to report in aggregate.

The instrument included a short introduction to the purpose of the study, procedures of the survey, and a consent form. A video was incorporated to ensure all participants had a baseline understanding of VR technology as a mechanism for flight training. The first set of questions determined participant eligibility to participate in the study in 4 questions. The second set of 11 questions collected demographic information. The final section included 34 measurement items for examining the factors of the model. The constructs were assessed using three to five indicator variables (see Table 7) with responses gauged on a 5-point Likert response format ranging from "strongly disagree" or "no confidence" (1) to "strongly agree" or "total confidence" (5).

\subsection{Data analysis}

Data analysis consisted of descriptive statistical analysis, CFA, and full structural model testing. Demographic data were used to examine the sample profile to evaluate representativeness and included gender, ethnicity, age, institution, flight hours and certification, VR experience, gaming experience, and school standing. Descriptive statistics were used to determine the maximum, minimum, mean, and standard deviation of the data as appropriate.

A CFA and SEM were used to test the relationship of the indicator variables to the factors as well as the relationships between the factors. IBM's SPSS AMOS was utilized for the CFA and SEM. Model fit values were assessed per Byrne (2010) and Hair et al. (2010). The Comparative Fit Index (CFI) minimum value was 0.93. The Goodness of Fit (GFI), Adjusted GFI (AGFI), and Normed Fit Index (NFI) values were, ideally, greater than or equal to 0.90 . The CMIN/df should be less than or equal to 3 . Finally, the Root Mean Square Error of Approximation (RMSEA) maximum value was 0.06 . A post hoc and model respecification process was followed to increase model fit. Modification indices (MIs) were reviewed for high values that may indicate relationships between error terms or a cross-loading situation between items and factors. Error terms were correlated with high modification index values. The post hoc analysis is an iterative process, in which changes were made to the model one at a time based on the examination of MIs and review of relevant literature.

Multiple types of reliability and validity were evaluated. SPSS, AMOS, and Excel were used to assess reliability and validity. Cronbach's alpha was used to test the reliability of the survey items and the constructs. Composite reliability was calculated to determine the extent to which measured variables represented the construct it should measure, with a minimum value of 0.7 (Hair et al. 2010). Construct validity was tested using a pilot survey followed by the full study (Fussell and Truong 2020). Factor loadings were reviewed to ensure convergent validity and items with poor factor loadings (less than 0.7) were reviewed for deletion or rewording (Byrne 2010; Hair et al. 2010). Discriminant validity was tested using the heterotrait-monotrait ratio of correlations (HTMT; Henseler et al. 2015), a ratio to estimate the true correlation between constructs; a good indicator value was less than 0.85 , but less than 0.90 , was acceptable (Henseler et al. 2015; Kline 2016). 


\section{Results}

\subsection{Demographics}

Approximately 8000 flight students enrolled in Pilots Schools in the U.S. were contacted to achieve a minimum of 475 valid responses. Responses from participants who did not meet all of the requirements to complete the survey or who did not complete the survey in its entirety were removed from the data set. A total of 704 responses were completed in the time frame, of which 607 were valid cases. A review of the response rates revealed that a minimum response rate of $6 \%$ was needed, based on school size and the actual response rate of smaller institutions to ensure an adequate number of responses per school were utilized; responses from 22 institutions were analyzed. After cleaning the data in SPSS, 489 cases were available for analysis.
Participants ranged in age from 18 to $51(M=21.74$, $S D=4.78)$. Flight hours in an aircraft ranged from $1 \mathrm{~h}$ to $3,000 \mathrm{~h}(M=139.12, S D=180.01)$. Hours logged in a flight training device (often used during flight training for varying levels of certification) ranged from $0 \mathrm{~h}$ to $1,000 \mathrm{~h}$ $(M=26.22, S D=51.40)$. The participants ranged in highest level of flight certification from student pilot $(n=139$, $28.4 \%)$ to airline transport pilot $(n=1,0.2 \%)$. Participant education also varied. The majority identified as undergraduate students in a four-year degree program $(n=446)$. Table 1 highlights the basic demographic attributes of the aviation students.

A Chi-square test for independence was used to assess if the gender distribution of the sample was comparable to that of the sampling framework. Based on consultation with the institutions and other sources (Federal Aviation Administration, 2020; Women In Aviation, n.d.), the expected distribution was $85 \%$ male and $15 \%$ female. The observed distribution was $85.89 \%$ male, $13.70 \%$ female, and $0.41 \%$ prefer not

Table 1 Summary of selected Demographic data

\begin{tabular}{|c|c|c|c|}
\hline Attribute & Subgroup categories & Frequency & Percentage \\
\hline \multirow[t]{3}{*}{ Gender } & Female & 67 & 13.7 \\
\hline & Male & 420 & 85.9 \\
\hline & Other/Prefer not to say & 2 & 0.4 \\
\hline \multirow[t]{5}{*}{ Current education status: Undergraduate } & Freshman & 104 & 21.3 \\
\hline & Sophomore & 121 & 24.7 \\
\hline & Junior & 119 & 24.3 \\
\hline & Senior & 102 & 20.9 \\
\hline & Graduated but continuing flight lessons or another certificate on campus & 4 & 0.8 \\
\hline \multirow[t]{6}{*}{ Current education status: Graduate } & First year & 7 & 1.4 \\
\hline & Second year & 7 & 1.4 \\
\hline & Third year & 5 & 1.0 \\
\hline & Fourth year & 2 & 0.4 \\
\hline & Fifth year or beyond & 5 & 1.0 \\
\hline & Other/Did not specify & 12 & 2.4 \\
\hline \multirow[t]{7}{*}{ Highest level of flight certification received } & Airline transport pilot & 1 & 0.2 \\
\hline & Instructor (including single engine, multi-engine, instrument) & 26 & 5.3 \\
\hline & Commercial pilot & 42 & 8.6 \\
\hline & Multi-engine & 8 & 1.6 \\
\hline & Private pilot & 170 & 34.8 \\
\hline & Private pilot, instrument flight rating & 103 & 21.1 \\
\hline & Student pilot & 139 & 28.4 \\
\hline \multirow[t]{4}{*}{ Experience with VR } & I have never used VR & 149 & 30.5 \\
\hline & I have used VR a couple of times but am not a frequent user & 297 & 60.7 \\
\hline & I use VR a few times a week & 35 & 7.2 \\
\hline & I use VR daily & 8 & 1.6 \\
\hline \multirow[t]{4}{*}{ Experience with computer or video gaming } & I have some gaming experience & 130 & 26.6 \\
\hline & I play computer/video games less than once a week & 139 & 28.4 \\
\hline & I play computer/video games a few times per week, but not daily & 125 & 25.6 \\
\hline & I play computer/video games daily & 95 & 19.4 \\
\hline
\end{tabular}


to say. The gender categories occurred within the specified probabilities, $p=0.44$.

\subsection{Measurement model}

The CFA included assessing the results of the study for normality, missing data, outliers, model fit follow by respecification as appropriate, reliability, and validity. Normality was checked in SPSS and also in AMOS. All values in the dataset, including outliers, had a kurtosis value below 2.0 for the original model and subsequent iterations; a value less than 3.0 was acceptable (Byrne 2010). No data was missing from the dataset after the data was cleaned. Mahalanobis D-square values were examined in the CFA output to determine if outliers were present, with those values greater than 100 representing extreme outliers. Five observations were identified; these were iteratively removed during the model respecification process for a final sample size of 484 .

The Maximum Likelihood Estimate (MLE) was utilized to assess the model fit (Hair et al. 2010). The original model had a slightly low model fit; thus, the decision was made to iteratively run post hoc analyses to respecify the model. This process entailed systematically reviewing the MIs in the CFA output and making adjustments to the model, reviewing outliers and removing them, and assessing the reliability and validity of the model. Hair et al. (2010) note the goodness of fit measures may become more sensitive to a very large sample size. Particularly, the Goodness of Fit Index (GFI) and the Adjusted Goodness of Fit Index (AGFI) may be affected and should be considered secondary indicators, greater than or equal to 0.90 . Covariance between error terms was reviewed as were regression weights between items and factors which may suggest cross-loading.

The first specified CFA model had mixed results in terms of model fit, factor loadings, covariances, cross-loadings, AVE and convergent validity, discriminant validity, and construct reliability and Cronbach's alpha values. The model was evaluated, and it was determined that the PHR factor and the item SE3 may need to be removed to improve the model. The literature was reviewed to confirm the process
(Hair et al. 2010). The iterative process included first removing PHR items and repeating the respecification process to evaluate model fit, reliability, and validity. By the end of the process, the PHR factor, the three PHR indicator items, and SE3 were removed. A review of the CFA output of normality revealed no change in kurtosis (e.g., all remained under 2.0). Table 2 details the model fit indices of the final CFA model, shown in Fig. 2. The Chi-square value of the final specified model was $804.63(\mathrm{df}=369, p=0.000)$. The model fit was deemed acceptable.

The reliability and validity of the first specified model had mixed values across the constructs and model fit indices. In general, the reliability and validity values of the model remained the same or increased with the removal of the PHR factor and items. The final values were all greater than the minimum values except RU. The factor had low construct reliability of 0.63 and a low (but acceptable) Cronbach's alpha of 0.71 . However, removing RU items did not increase model fit; thus, the factor was retained. Table 3 describes the construct reliability of the final CFA model, while Table 4 highlights the convergent validity assessment using HTMT. The reliability and validity of the model were acceptable.

\subsection{Measurement model}

The final CFA model, represented in Fig. 2, was transformed into an SEM model. The removal of construct PHR meant it was unnecessary to test hypothesis 8 . MIs were reviewed for regression weights between factors that indicate a potential, new relationship. Only one possible new relationship was identified for review and potential inclusion in the model: PENJ impacts BI $(\mathrm{MI}=13.43)$. The relationship has support in the literature (Lee et al. 2018b; Manis \& Choi 2018) and was included and tested in the final SEM. Results indicated sufficient evidence to conclude that PENJ has a positive influence on BI. Adding the PENJ-BI relationship resulted in a modified SEM, shown in Fig. 3, and improved model fit values, detailed in Table 5. The relationship is $\mathrm{H}_{15}$ : "Perceived enjoyment positively influences behavioral intention.” Hypothesis testing results are described in Table 6.
Table 2 Model fit indices of the final CFA model

\begin{tabular}{lllll}
\hline Model fit index & Acceptance value & Original model & $\begin{array}{l}\text { First specified } \\
\text { model }\end{array}$ & $\begin{array}{l}\text { Final speci- } \\
\text { fied model }\end{array}$ \\
\hline CFI & $\geq 0.93$ & 0.93 & 0.96 & 0.97 \\
GFI & $\geq 0.90$ & 0.85 & 0.89 & 0.90 \\
AGFI & $\geq 0.90$ & 0.82 & 0.86 & 0.87 \\
NFI & $\geq 0.90$ & 0.91 & 0.93 & 0.94 \\
CMIN/df & $\leq 3.00$ & 2.87 & 2.12 & 2.18 \\
RMSEA & $\leq 0.06$ & 0.06 & 0.05 & 0.05 \\
\hline
\end{tabular}

Large sample sizes make these values more sensitive and may indicate poor model fit. Adapted from "Determinants of Aviation Students' Intentions to use Virtual Reality for Flight Training" by S. G. Fussell, 2020 , in press 


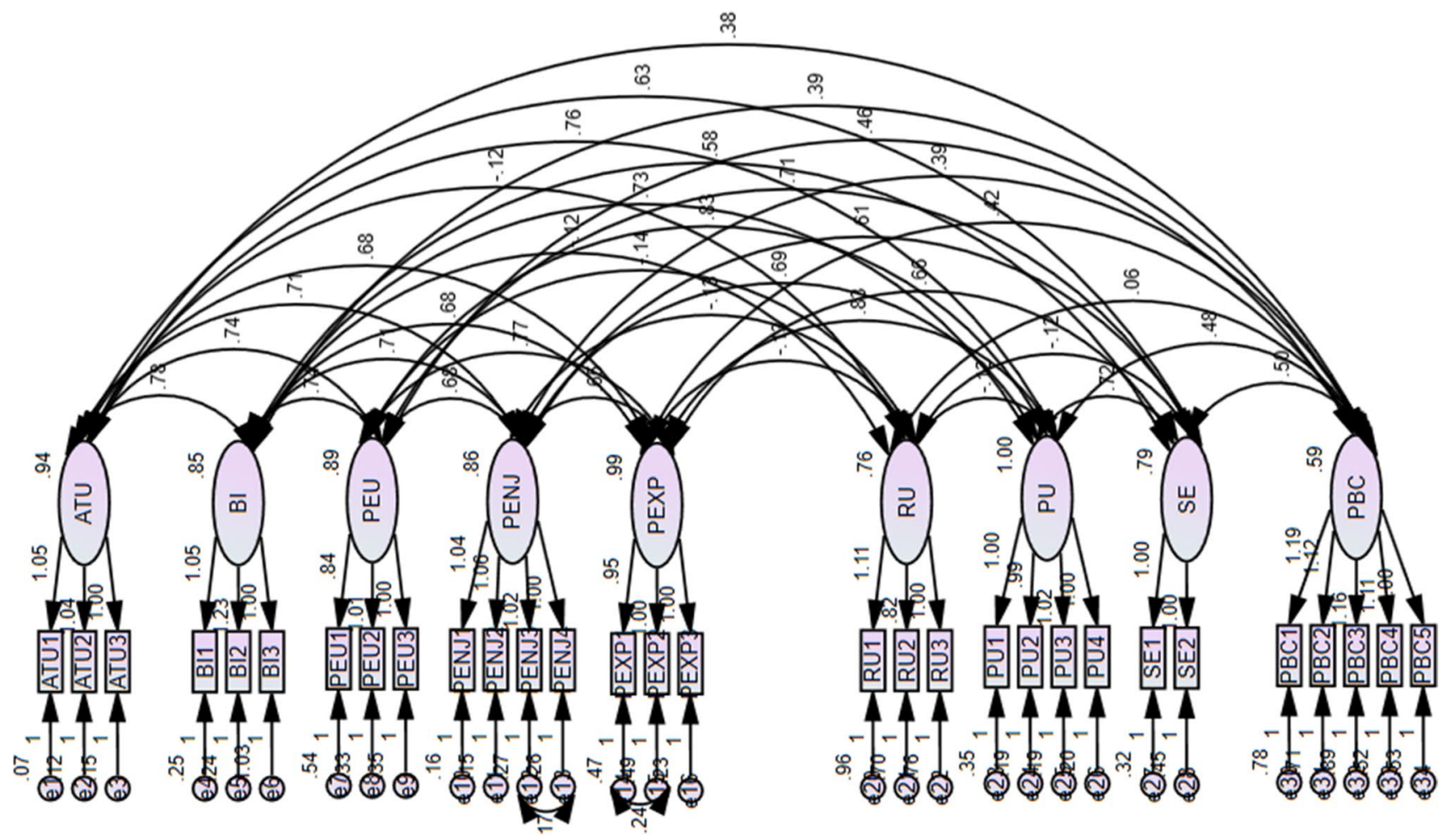

Fig. 2 The final specified CFA model

\section{Discussion}

This study assessed factors that influence students' attitude toward and intention to use virtual reality (VR) for training. The context of this study was flight students considering VR for flight training in a theoretical capacity. The constructs and relationships utilized in the study were supported by the literature surrounding education and training, aviation, and VR; using other types of immersive simulation technology for training in general and specifically for aviation education; and the ground theories of the TAM, the TPB, and combinations thereof.

The final sample size was 484. Participants ranged in age from 18 to 51 and represented varying levels of educational status and flight certification. Although all participants had begun flight training, their experience was quite varied, ranging from new student pilots $(1 \mathrm{~h}$.) to advanced certification (i.e., airline transport pilot) and hours (3000 h.). In general, participants were not frequent users of VR, although the majority had some experience with the technology. Only a small percentage (9\%) reported frequent or even daily use of VR. Despite the overall limited familiarity of VR, over half of the participants reported they played computer or video games frequently (i.e., a few times a week or daily).
In general, about half of American adults play video games on a computer, game console, TV, or portable device (Duggan 2015). The characteristics of the sample align well with general, known characteristics of the target population and provide insight into the results of the structural model.

\subsection{Discussion of the research questions}

The first and second research questions asked, "What factors influence students' intentions to use VR technology for training?" and "How do these factors impact students' intentions to use VR technology for training?" The original CFA model identified 10 latent factors, eight of which were used in the final SEM as direct or indirect influencers of BI. The factor of PEU had the strongest indirect and direct, positive influence on ATU, and a strong, positive, indirect impact on BI. The relationship is part of the original TAM (Davis et al. 1989) and is supported by the literature. As expected from the literature, ATU also strongly influenced BI. The other factors that influence ATU and BI, directly and indirectly, are PU, PENJ, and PBC. Of interest, SE was an indirect, positive influencer of BI through PEU, yet had a negative, direct impact on ATU, which was statistically insignificant. Neither RU nor PEXP impacted ATU as hypothesized. 
Table 3 Construct validity of the final specified CFA model

\begin{tabular}{|c|c|c|c|c|}
\hline Construct & Item & $\begin{array}{l}\text { Factor loading } \\
(\geq 0.7, \text { min } 0.5)\end{array}$ & $\begin{array}{l}\text { Construct reliabil- } \\
\text { ity }(\geq 0.7)\end{array}$ & $\begin{array}{l}\text { Cronbach's } \\
\text { alpha }(\geq 0.7)\end{array}$ \\
\hline \multirow[t]{3}{*}{ Attitude toward use } & ATU1 & 0.97 & \multirow[t]{3}{*}{0.96} & \multirow[t]{3}{*}{0.96} \\
\hline & ATU2 & 0.95 & & \\
\hline & ATU3 & 0.93 & & \\
\hline \multirow[t]{3}{*}{ Behavioral intention } & BI1 & 0.89 & \multirow[t]{3}{*}{0.80} & \multirow[t]{3}{*}{0.85} \\
\hline & BI2 & 0.92 & & \\
\hline & $\mathrm{BI} 3$ & 0.67 & & \\
\hline \multirow[t]{5}{*}{ Perceived behavioral control } & $\mathrm{PBC} 1$ & 0.72 & \multirow[t]{5}{*}{0.79} & \multirow[t]{5}{*}{0.84} \\
\hline & $\mathrm{PBC} 2$ & 0.71 & & \\
\hline & PBC3 & 0.69 & & \\
\hline & PBC4 & 0.76 & & \\
\hline & PBC5 & 0.72 & & \\
\hline \multirow[t]{4}{*}{ Perceived enjoyment } & PENJ1 & 0.92 & \multirow[t]{4}{*}{0.94} & \multirow[t]{4}{*}{0.95} \\
\hline & PENJ2 & 0.93 & & \\
\hline & PENJ3 & 0.88 & & \\
\hline & PENJ4 & 0.88 & & \\
\hline \multirow[t]{3}{*}{ Perceived ease of use } & PEU1 & 0.73 & \multirow[t]{3}{*}{0.83} & \multirow[t]{3}{*}{0.85} \\
\hline & PEU2 & 0.86 & & \\
\hline & PEU3 & 0.85 & & \\
\hline \multirow[t]{3}{*}{ Performance expectancy } & PEXP1 & 0.81 & \multirow[t]{3}{*}{0.84} & \multirow[t]{3}{*}{0.90} \\
\hline & PEXP2 & 0.82 & & \\
\hline & PEXP3 & 0.90 & & \\
\hline \multirow[t]{4}{*}{ Perceived usefulness } & PU1 & 0.86 & \multirow[t]{4}{*}{0.93} & \multirow[t]{4}{*}{0.94} \\
\hline & PU2 & 0.91 & & \\
\hline & PU3 & 0.92 & & \\
\hline & PU4 & 0.91 & & \\
\hline \multirow[t]{3}{*}{ Regulatory uncertainty } & RU1 & 0.70 & \multirow[t]{3}{*}{0.63} & \multirow[t]{3}{*}{0.71} \\
\hline & RU2 & 0.65 & & \\
\hline & RU3 & 0.71 & & \\
\hline \multirow[t]{2}{*}{ Self-efficacy } & SE1 & 0.84 & \multirow[t]{2}{*}{0.78} & \multirow[t]{2}{*}{0.80} \\
\hline & SE2 & 0.80 & & \\
\hline
\end{tabular}

The original CFA model required modifications to improve the model fit as well as reliability and validity. The relationship between PHR and ATU (hypothesis 8) was removed during the CFA process due to low reliability and validity values associated with the factor and its items, as the factor and its items negatively impacted model fit. It was hypothesized that perceptions of health risks associated with using VR for training may negatively impact acceptance and ATU. Students who learn in dynamic learning environments may be comfortable using some types of advanced, immersive simulation technology for their training. Students may not have concerns about health risks associated with VR if they have little firsthand knowledge of them (e.g., simulation sickness). Students in other dynamic learning environments may have a similar experience with VR and may not know the potential health risks associated with using VR in a dynamic learning environment.

The final research question was "To what extent do these factors influence students' intentions to use VR technology for training?" The model fit of the final, modified SEM was good with all indices indicating acceptable value or greater. Table 5 details these indices, which were used as the main confirmation of how well the model described the factors that influence students' intentions to use VR technology in a dynamic learning environment. One hypothesis $\left(\mathrm{H}_{8}\right)$ was removed due to the deletion of PHR. A new relationship between PENJ and BI $\left(\mathrm{H}_{15}\right)$ was discovered and supported. The removal of $\mathrm{H}_{8}$ and the addition of $\mathrm{H}_{15}$ resulted in support of nine out of 14 hypotheses (64\%). The addition of the new relationship indicates that although the original model 
Table 4 HTMT Assessment of final specified CFA model

\begin{tabular}{lclc}
\hline Correlation & HTMT ratio & Correlation & HTMT ratio \\
\hline ATU $<->$ PEU & 0.81 & PEXP $<->$ PU & 0.80 \\
ATU $<->$ PENJ & 0.77 & PEXP $<->$ SE & 0.70 \\
ATU $<->$ PEXP & 0.85 & PEXP $<->$ PBC & 0.50 \\
ATU $<->$ RU & -0.14 & RU $<->$ PU & -0.15 \\
ATU $<->$ PU & 0.78 & RU $<->$ SE & -0.13 \\
ATU $<->$ SE & 0.73 & RU $<->$ PBC & 0.09 \\
ATU $<->$ PBC & 0.51 & PU $<->$ SE & 0.83 \\
PEU $<->$ PENJ & 0.77 & PU $<->$ PBC & 0.63 \\
PEU $<->$ PEXP & 0.74 & SE $<->$ PBC & 0.72 \\
PEU $<->$ RU & -0.16 & $\mathrm{ATU}<->$ BI & 0.88 \\
PEU $<->$ PU & 0.87 & $\mathrm{BI}<->$ PEU & 0.90 \\
PEU $<->$ SE & 0.86 & $\mathrm{BI}<->$ PENJ & 0.82 \\
PEU $<->$ PBC & 0.64 & $\mathrm{BI}<->$ PEXP & 0.75 \\
PENJ $<->$ RU & -0.26 & $\mathrm{BI}<->$ RU & -0.16 \\
PENJ $<->$ PU & 0.89 & $\mathrm{BI}<->$ PU & 0.83 \\
PENJ $<->$ SE & 0.74 & $\mathrm{BI}<->$ SE & 0.73 \\
PENJ $<->$ PBC & 0.54 & $\mathrm{BI}<->$ PBC & 0.57 \\
PEXP $<->$ RU & -0.17 & & \\
\hline
\end{tabular}

was fit and adequately answered the research question, it was slightly lacking in depicting all pertinent relationships.

\section{Conclusions and future research}

The purpose of this study was to determine factors that influence students' attitude toward and intention to use VR for training, through the context of VR for flight training. The extended TAM investigated VR technology in a dynamic learning environment and encompassed new factors that are relevant to the technology and educational environment.

The results of the research have several theoretical implications. First, the study contributes to the body of knowledge surrounding using VR in dynamic learning environments. The model validated that established factors of the TAM and TPB may be extended and applied to VR technology as well as dynamic learning environments. The validated model may be further adapted to assess user perception of other types of immersive simulation technology as well as other dynamic education and training environments. Second, the model further validated factors that may be relevant to understanding student intention toward using VR for training. PEXP and PENJ were validated as important factors to assess attitude toward and intention to used VR technology in a dynamic learning environment. Although the factors of PEXP and PENJ have been validated for the context of the present study, these factors warrant further investigation as they had unsupported hypotheses. The positive yet insignificant relationship between PEXP and ATU may have been impacted by the users' lack of experience with VR in general; participants had to consider using VR in a dynamic learning environment from a theoretical standpoint. The relationship may be stronger when users have more experience with VR and can compare using the technology to other simulators and training devices. The negative relationship between PBC and PEU is a discovery that is not supported by the theorized relationship; because users indicated low experience with VR, they may have little knowledge on which to base their ability to use the technology for training purposes. It is possible that students may not adopt VR in a dynamic learning environment if they do not understand how it works nor how it will benefit their training. Instructors and developers may need to first demonstrate the benefits of using VR in a dynamic learning environment.

Additionally, the study demonstrates that the model is a useful tool to understand how students perceive using VR in a dynamic learning environment. This model may be adapted for use by researchers for use in other dynamic educational or training environments where VR is being considered as a training instrument. The survey instrument and methodology may provide insight into students' attitudes toward and intention to use VR in other dynamic learning environments. The verbiage of the survey instrument could be adapted for other immersive simulation technologies, such as augmented reality, mixed reality, or simulators used in part-task training, and for other user groups. With proper revision, the survey instrument and model may be validated or extended for use in a variety of research contexts, populations, and technologies. For example, it could be adapted for use in medical training on virtual patients and procedures, augmenting the learning and practice of an assembly process of a complex mechanism, or simulating a space operations flight with simulated. This would allow for more understanding of how these factors explain user behavior with similar technologies. Specifically, the factors of PENJ, PEXP, SE, and $\mathrm{PBC}$ require more investigation in the realm of VR and other immersive simulation technologies.

Practically, the results provide insight into the student perspective. VR can benefit training, but how the technology is introduced and incorporated into the curriculum may impact student attitude, acceptance, and intent to use it. Participants responded as having low experience with VR, and the technology may not be readily accessible for use; this undoubtedly impacted their perspective of using the technology for training. User familiarity with the technology, and therefore confidence in using it, may be low. Students may 


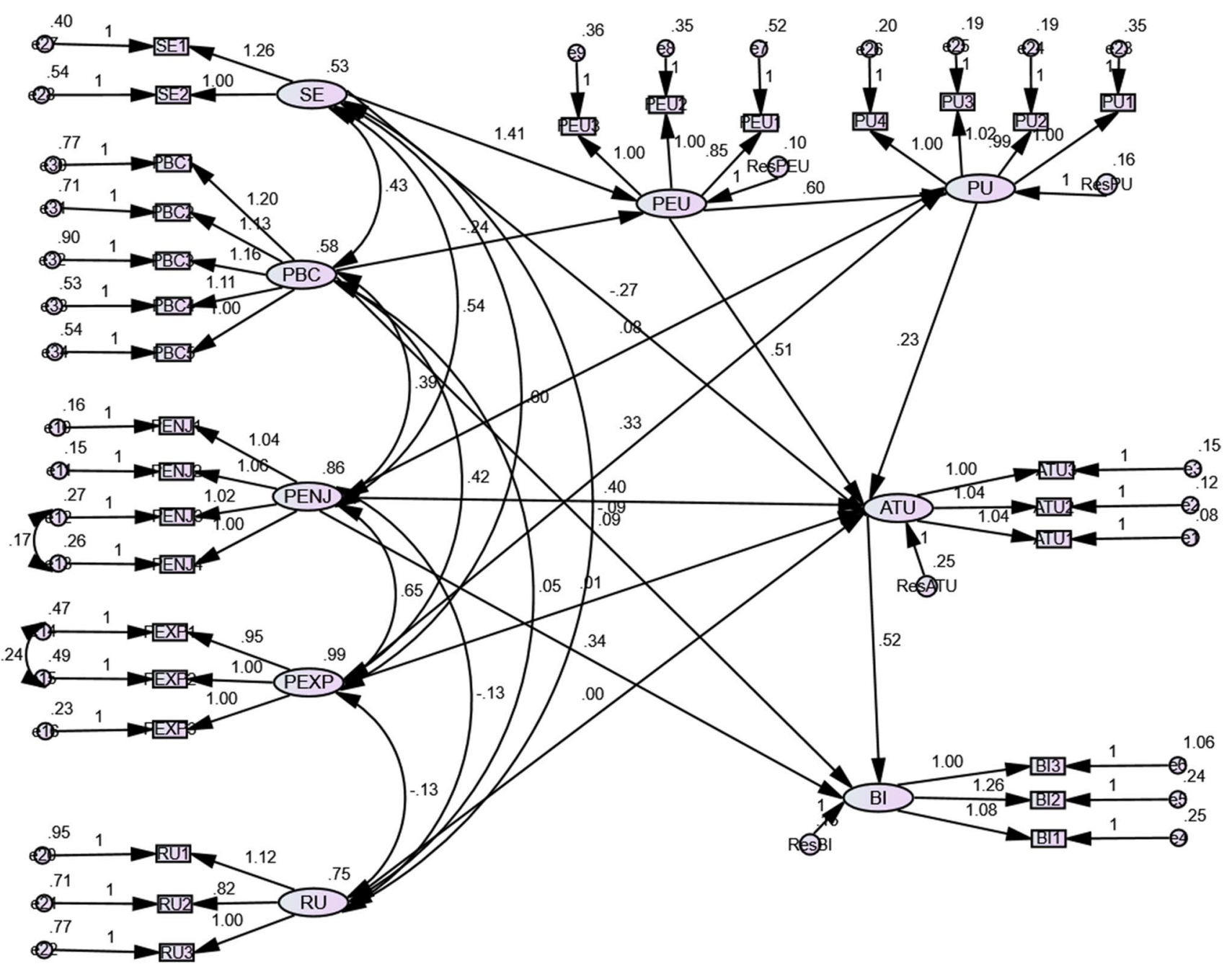

Fig. 3 The Modified SEM with standardized regression weights

Table 5 Model fit indices of the original and final SEMs

\begin{tabular}{llll}
\hline Model fit index & Acceptance value & Original SEM & Final SEM \\
\hline CFI & $\geq 0.93$ & 0.96 & 0.96 \\
GFI & $\geq 0.90$ & 0.88 & 0.89 \\
AGFI & $\geq 0.90$ & 0.86 & 0.86 \\
NFI & $\geq 0.90$ & 0.93 & 0.94 \\
CMIN/df & $\leq 3.00$ & 2.40 & 2.28 \\
RMSEA & $\leq 0.06$ & 0.05 & 0.05
\end{tabular}

Large sample sizes make these values more sensitive and may indicate poor model fit benefit from understanding the advantages of learning with VR and gaining familiarity with the technology before it is incorporated as a training tool. The factors PHR and RU may not be of importance to students at this time, but that stance may change as VR becomes more available and is incorporated into the curriculum and federal regulations associated with flight training at Pilot Schools. Although PEXP did not influence ATU, the factors of PEU, PU, and PENJ were found to influence ATU directly. This perspective is insightful as it implies that students will be more willing to use VR for training if it is easy to use and will improve performance. Students must already prioritize their resources (e.g., time, finances) and if the student does not perceive that VR will 
Table 6 Hypothesis testing of the final structural model

\begin{tabular}{lccll}
\hline Hypothesis/Relationship & SRW & t-value & $P$ value & Result \\
\hline $\mathrm{H}_{1}:$ PEU positively influences PU & 0.60 & 8.90 & $* * *$ & Supported \\
$\mathrm{H}_{2}:$ PEU positively influences ATU & 0.51 & 3.35 & $* * *$ & Supported \\
$\mathrm{H}_{3}$ : PU positively influences ATU & 0.23 & 2.67 & 0.008 & Supported \\
$\mathrm{H}_{4}:$ PEXP positively influences PU & 0.34 & 6.26 & $* * *$ & Supported \\
$\mathrm{H}_{5}:$ PEXP positively influences ATU & 0.01 & 0.08 & 0.940 & Not supported \\
$\mathrm{H}_{6}:$ PENJ positively influences PU & 0.08 & 1.69 & 0.095 & Not supported \\
$\mathrm{H}_{7}:$ PENJ positively influences ATU & 0.40 & 7.15 & $* * *$ & Supported \\
$\mathrm{H}_{8}:$ PHR negatively influences ATU & - & - & - & Removed, not tested \\
$\mathrm{H}_{9}:$ RU negatively influences ATU & 0.00 & 0.13 & .900 & Not supported \\
$\mathrm{H}_{10}:$ SE positively influences PEU & 1.41 & 12.16 & $* * *$ & Supported \\
$\mathrm{H}_{11}:$ SE positively influences ATU & -0.27 & -1.39 & 0.165 & Not supported \\
$\mathrm{H}_{12}$ : PBC positively influences PEU & -0.24 & -2.67 & 0.008 & Not supported \\
$\mathrm{H}_{13}:$ PBC positively influences BI & 0.09 & 2.29 & 0.022 & Supported \\
$\mathrm{H}_{14}:$ ATU influences BI & 0.52 & 10.41 & $* * *$ & Supported \\
$\mathrm{H}_{15}$ : PENJ positively influences BI & 0.34 & 6.87 & $* * *$ & New hypothesis, Supported \\
\hline
\end{tabular}

**** Indicates significance at $p<0.001$. The critical ratio t-values should be above 1.96 with $p$ values below 0.05 to indicate support for a hypothesis. $\mathrm{SRW}=$ Standardized regression weight be beneficial for training, they will likely use other devices. Instructors, curriculum developers, and others can use this knowledge to design programs to educate students on how to use VR, the benefits of using VR for training, and encourage them to use VR for personal use to increase familiarity with and enjoyment of the technology.

This model can be adapted for use by other researchers to gain insight into students' attitudes toward and intention to use VR for training or educational purposes in different environments. The verbiage of the survey instrument can be modified for other immersive simulation technologies, including augmented reality, mixed reality, and simulators used in part-task training. This would enable a better understanding of how these factors explain user behavior with similar but less immersive technologies. Replication can validate the model and survey instrument and allow for comparison between training environments and populations. Other researchers may consider examining the factors of PENJ, PEXP, SE, and PBC in the realm of immersive simulation technologies.

This study has three main limitations. Although these limitations constrain the results of the study, the findings are no less diminished. First, the representation of this study may be limited. Although the findings are based on data collected from students at higher education institutions, the results may not generalize to all higher education students. However, results may be used to inform educators and instructors who are considering incorporating VR into other dynamic learning environments. Second, data were collected using a cross-sectional survey design over two months in 2020. Participants responded subjectively and in a theoretical capacity. The findings should not be generalized beyond the time period. A third limitation is the factors used in the model. The scope of the study limited the factors to those relevant to VR, immersive simulation technologies, and dynamic learning environments. Other factors that may be relevant, but were not incorporated into the model, may provide more context.

Future research should examine the factors of the model and revise them as appropriate. The factor of PHR should be reexamined as it was removed from the model in this study. Users may be unaware of the physical health risks associated with VR, as they are not very experienced with using the technology. The factor SE and its items should be reviewed for future inclusion in the model. Additional research into how SE is affected by belief in one's abilities and VR experience is also suggested. Finally, more research surrounding how PBC, PEXP, and PENJ influence ATU and $\mathrm{BI}$ in dynamic learning environments and accepting VR 


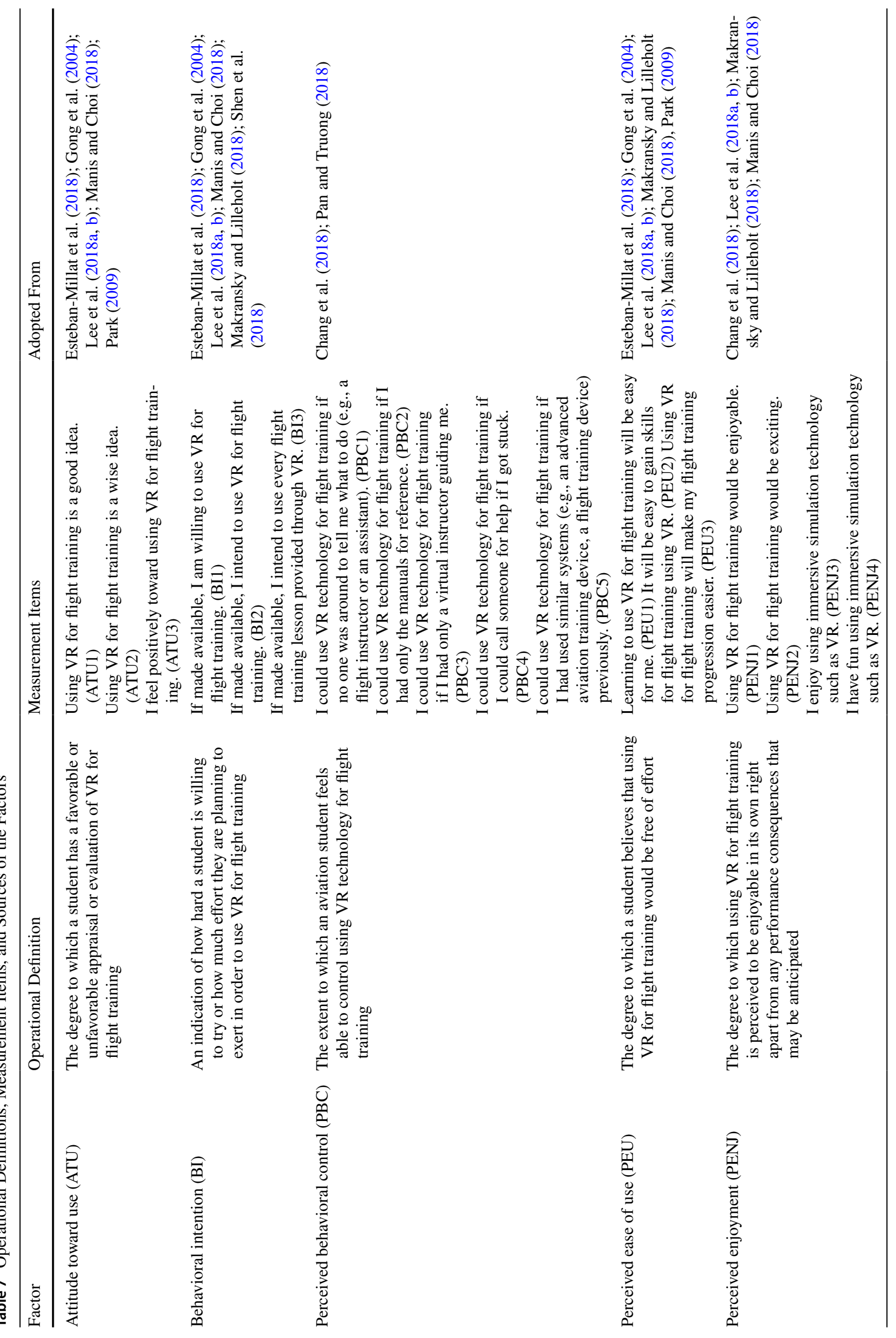




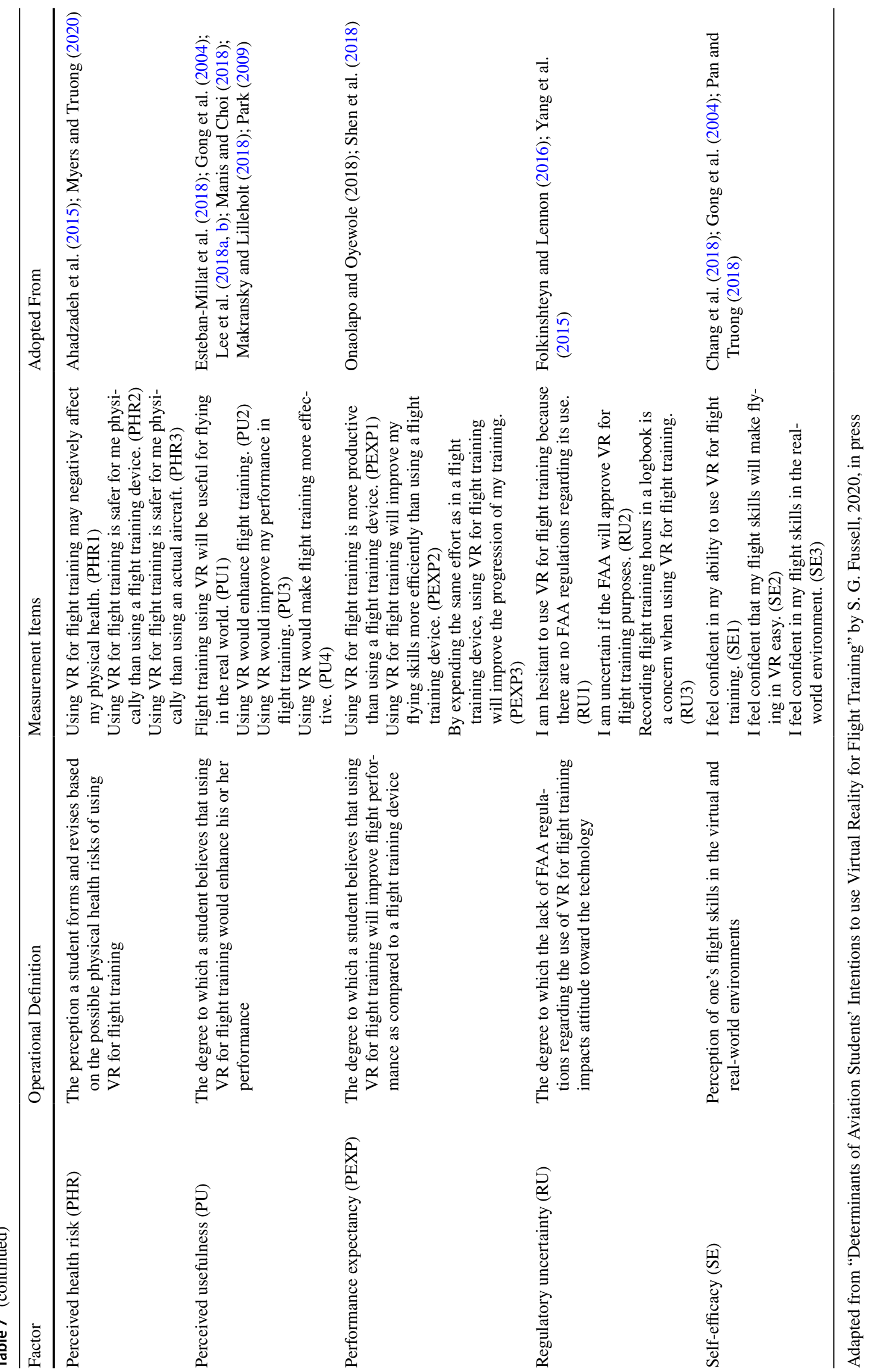


technology for training purposes, is recommended. These factors have limited use in the context of the study, and further research will validate their importance as determinants of ATU and BI in an extended TAM.

\section{Appendix 1}

\section{See Table 7}

Acknowledgements Not applicable.

Author contributions Both authors have approved the manuscript for submission. Dr. Fussell collected and analyzed the data and wrote the manuscript. Dr. Truong supervised data collection, reviewed and advised the data analyses, and edited the manuscript.

Funding No funding was used for this research.

Availability of data and material This data is not available.

Code availability Not applicable.

\section{Declarations}

Conflict of interest There are no issues related to the journal policies, nor are there any competing interests.

Consent to participate All participants of the study agreed to the informed consent document. All data were anonymous to protect the participants. IRB approval was gained from the author's institution and from participating institutions as required.

\section{References}

Abdullah F, Ward R (2016) Developing a general extended technology acceptance model for E-learning (GETAMEL) by analyzing commonly used external factors. Comput Hum Behav 56:238-256. https://doi.org/10.1016/j.chb.2015.11.036

Abdullah F, Ward R, Ahmed E (2016) Investigating the influence of the most commonly used external variables of TAM on students' perceived ease of use (PEOU) and perceived usefulness (PU) of e-portfolios. Comput Hum Behav 63:75-90. https://doi.org/10. 1016/j.chb.2016.05.014

Ahadzadeh AS, Pahlevan Sharif S, Ong FS, Khong KW (2015) Integrating health belief model and technology acceptance model: An investigation of health-related internet use. J Med Internet Res 17(2):e45. https://doi.org/10.2196/jmir.3564

Ajze I (1991) The theory of planned behavior. Organizational Behavior and Human Decision Processes 50, 179-211. https://pdfs.seman ticscholar. org/6256/ca4853f44ab9acb98f91f0d7848c54185ca7. pdf

Bandura A (1991) Social cognitive theory of self-regulation. Organ Behav Hum Decis Process 50:248-287

Bürki-Cohen J and Go TH (2005) The effect of simulator motion cues on initial training of airline pilots. Proceedings of the AIAA Modeling and Simulation Technologies Conference and Exhibit
(AIAA 2005-6109). San Francisco, CA. https://doi.org/10.2514/6. 2005-6109

Bürki-Cohen J, Sparko A and Go TW (2007) Training value of a fixed-base flight simulator with a dynamic seat. Proceedings of the AIAA Modeling and Simulation Technologies Conference and Exhibit (AIAA 2007-6564), Hilton Head, SC. https://doi. org/10.2514/6.2007-6564

Byrne BM (2010) Structural equation modeling with AMOS. Taylor and Francis Group, New York

Cardullo FM, Stanco A, Kelly L, Houck J and Grube R (2011) A transfer of training study of control loader dynamics [Paper presentation]. Proceedings of the AIAA Modeling and Simulation Technologies Conference, Portland, OR. https://doi.org/ 10.2514/6.2011-6349

Chang C, Heo J, Yeh S, Han H, Li M (2018) The effects of immersion and interactivity on college students' acceptance of a novel VR-supported educational technology for mental rotation. IEEE Access 6:66590-66599. https://doi.org/10.1109/ACCESS.2018. 2878270

Cheung R, Vogel D (2013) Predicting user acceptance of collaborative technologies: An extension of the technology acceptance model for e-learning. Comput Educ 63:160-175

Davis FD (1989) Perceived usefulness, perceived ease of use, and user acceptance of information technology. MIS Q 13(3):319340. https://doi.org/10.2307/249008

Davis FD, Bagozzi RP, Warshaw PR (1989) User acceptance of computer technology: A comparison of two theoretical models. Manage Sci 35(8):982-1003. https://doi.org/10.1287/mnsc. 35.8.982

Duggan M (2015). Gaming and gamers. Pew Research Center, December 2015. Retrieved from https://www.pewresearch.org/internet/ 2015/12/15/gaming-and-gamers/

Eastgate RM, Wilson JR and D'Cruz M (2015) Structure development of Virtual Environments. In K. S. Hale, K. M. Stanney, and D. M. Badcock (Eds.), The handbook of virtual environments: Design, implementation, and applications (2nd ed.) (pp. 353-390). CRC Press.

Esteban-Millat I, Martínez-López FJ, Pujol-Jover M, Gázquez-Abad JC, Alegret A (2018) An extension of the technology acceptance model for online learning environments. Interact Learn Environ 26(7):895-910. https://doi.org/10.1080/10494820.2017.1421560

Folkinshteyn D, Lennon M (2016) Braving bitcoin: A technology acceptance model (TAM) analysis. Journal of Information Technology Case and Application Research 18(4):220-249. https://doi. org/10.1080/15228053.2016.1275242

Fussell SG, Derby JL, Smith JK, Shelstad WJ, Benedict JD, Chaparro BS, Thomas R, Dattel AR (2019) Usability testing of a virtual reality tutorial. Proceed Human Factors Ergon Soc Annual Meet 63(1):2303-2307. https://doi.org/10.1177/1071181319631494

Fussell SG and Hight M (2021) Usability testing of a VR flight training program. Lecture proposed for the 65th Human Factors and Ergonomics Society (HFES) International Annual Meeting, Baltimore, MD, 4-8,

Fussell SG and Truong D (2020) Preliminary results of a study investigating aviation student's intentions to use virtual reality for flight training [Paper presentation]. 32nd National Training Aircraft Symposium, Daytona Beach, FL, United States.

Gong M, Xu Y, Yu Y (2004) An enhanced technology acceptance model for web-based learning. J Inf Syst Educ 15(4):365

Hair JF, Black WC, Babin BJ, Anderson RE (2010) Multivariate data analysis. Pearson Prentice Hall, New Jersy

Henseler J, Ringle CM, Sarstedt M (2015) A new criterion for assessing discriminant validity in variance-based structural equation modeling. J Acad Mark Sci 43(1):115-135. https://doi.org/10. 1007/s11747-014-0403-8 
Hight MP, and Fussell SG (2021) Effectiveness of VR simulations: Comparing virtual reality with 2D simulations for ab initio pilot training. Journal of Aviation/Aerospace Education \& Research.

Huang F (2020) Adapting UTAUT2 to assess user acceptance of an e-scooter virtual reality service. Virtual Reality: J Virtual Reality Soc 24(4):635. https://doi.org/10.1007/s10055-019-00424-7

Jensen L, Konradsen F (2018) A review of the use of virtual reality head-mounted displays in education and training. Educ Inf Technol 23(4):1515-1529. https://doi.org/10.1007/s10639-017-9676-0

Jerald J (2016) The VR book: Human-centered design for virtual reality. Association for Computing Machinery.

King WR, He J (2006) A meta-analysis of the technology acceptance model. Inf Manage 43(6):740-755. https://doi.org/10.1016/j.im. 2006.05.003

Kline RB (2016) Principles and practice of structural equation modeling, 4th edn. Guilford Press, New York

Koglbauer I (2016) Simulator training improves pilots' procedural memory and generalization of behavior in critical flight situations. Cognition, Brain, Behavior 20(4):357-366

Landman A, van Oorschot P, van Paassen MM, Groen EL, Bronkhorst AW, Mulder M (2018) Training pilots for unexpected events: A simulator study on the advantage of unpredictable and variable scenarios. Human Factors: J Human Factors Ergon Soc 60(6):793-805. https://doi.org/10.1177/0018720818779928

Lee C, Wang SW, Hsu MK, Jan S (2018a) Air passenger's perception toward pre-flight safety briefing videos: Does it matter? J Air Transp Manag 72:20-31. https://doi.org/10.1016/j.jairtraman. 2018.07.004

Lee J, Kim J, Choi JY (2018b) The adoption of virtual reality devices: The technology acceptance model integrating enjoyment, social interaction, and strength of the social ties. Telematics Inform 39:37-48. https://doi.org/10.1016/j.tele.2018.12.006

Leland R, Rogers RO, Boquet A, and Glaser S (2009) An experiment to evaluate transfer of upset-recovery training conducted using two different flight simulation devices (DOT/FAA/AM-09/17). Department of Transportation, Federal Aviation Administration. https://www.academia.edu/32044967

Lewis CC, Fretwell CE, Ryan J, Parham JB (2013) Faculty use of established and emerging technologies in higher education: A unified theory of acceptance and use of technology perspective. Int J Higher Edu 2(2):22-34

Lewis J, and Livingston J (2018) Pilot Training Next: Breaking institutional paradigms using student-centered multimodal learning. Proceedings of Interservice/Industry Training, Simulation, and Education Conference (I/ITSEC) 2018, Orlando, FL.

Lin P-H, Yeh S-C (2019) How motion-control influences a VR-supported technology for mental rotation learning: From the perspectives of playfulness, gender difference and technology acceptance model. Int J Human-Comput Interaction 35(18):1736-1746

Lindgren R, Tscholl M, Wang S, Johnson E (2016) Enhancing learning and engagement through embodied interaction within a mixed reality simulation. Comput Educ 95:174-187. https://doi.org/10. 1016/j.compedu.2016.01.001

Lu J, Chou H, Ling P (2009) Investigating passengers' intentions to use technology-based self check-in services. Transp Res, Part E 45:345-356. https://doi.org/10.1016/j.tre.2008.09.006

Macchiarella ND, Brady T, and Lyon BS (2008) An application of high fidelity FTDs for ab initio pilot training: The way ahead. Collegiate Aviation Review, 26(1) https://doi.org/10.1109/dasc. 2005.1563375

Macchiarella ND, Liu D, Gangadharan SN, Vincenzi DA, and Majoros AE (2005) Augmented reality as a training medium for aviation/ aerospace application. Proceedings of the Human Factors and Ergonomics Society 49th Annual Meeting, 2174-2178. Orlando, FL, United States.
Macchiarella ND, and Meigs CD (2008). Virtual air traffic flight training device automated air traffic control. Journal of Aviation/ Aerospace Education \& Research, 18(1). http://commons.erau. edu/jaaer/vol18/iss1/4

Mahalil I, Yusof AM, and Ibrahim N (2020). A literature review on the usage of technology acceptance model for analysing a virtual reality's cycling sport applications with enhanced realism fidelity [Paper presentation]. 8th International Conference on Information Technology and Multimedia (ICIMU), Langkawi, Malaysia. https://doi.org/10.1109/ICIMU49871.2020.9243571

Makransky G, Lilleholt L (2018) A structural equation modeling investigation of the emotional value of immersive virtual reality in education. Edu Tech Res Dev 66(5):1141-1164. https://doi.org/ 10.1007/s11423-018-9581-2

Makransky G, Terkildsen TS, Mayer RE (2017) Adding immersive virtual reality to a science lab simulation causes more presence but less learning. Learn Instr. https://doi.org/10.1016/j.learninstr uc. 2017.12 .00

Manis KT, Choi D (2018) The virtual reality hardware acceptance model (VR-HAM): Extending and individuating the technology acceptance model (TAM) for virtual reality hardware. J Business Res. https://doi.org/10.1016/j.jbusres.2018.10.021 (in Press)

Maraj CS, Lackey SJ, Badillo-Urquiola KA, Ogreten SL, and Maxwell DB (2015) Empirically derived recommendations for training novices using virtual worlds. Proceedings of Interservice/Industry Training, Simulation and Education Conference (IT/TSEC), 2015, Orlando, FL.

McLean GMT, Lambeth S, Mavin T (2016) The use of simulation in ab initio pilot training. Int J Aviat Psychol 26(1-2):36-45. https:// doi.org/10.1080/10508414.2016.1235364

Myers PL III, Truong D (2020) A new research model for higher risk activities applied to the use of small unmanned aircraft for data gathering operations. J Intell Rob Syst 100:1617-1634. https:// doi.org/10.1007/s10846-020-01232-x

Palla A, Brent L, and Sikorski E (2018) Training with virtual reality: Lessons learned. In Proceedings of the Interservice/Industry Training, Simulation and Education Conference (I/ITSEC).

Pan JY, Truong D (2018) Passengers' intentions to use low-cost carriers: An extended theory of planned behavior model. J Air Transp Manag 69:38-48. https://doi.org/10.1016/j.jairtraman.2018.01. 006

Park SY (2009) An analysis of the technology acceptance model in understanding university students' behavioral intention to use e-learning. Educ Technol Soc 12(3):150-162

Pilot schools. 14 CFR §141. (2020). Retrieved from https://www.ecfr. gov/cgi-bin/text-idx?c=ecfrandsid $=08 \mathrm{~d} 5$ aaae $437611 \mathrm{fafca} 7110 \mathrm{e} 2$ 9c2d963andtpl=/ecfrbrowse/Title14/14cfr141_main_02.tpl

Pool DM, Harder GA, van Paassen MM (2016) Effects of simulator motion feedback on training of skill-based control behavior. J Guid Control Dyn 39(4):889-901. https://doi.org/10.2514/1. g001603

Reweti S, Gilbey A, Jeffrey L (2017) Efficacy of low-cost pc-based aviation training devices. J Inf Tech Edu: Res 16:127-142

Richardson C, Truong D, Choi WJ (2019) Examination of factors related to pilot acceptance behaviors toward the automatic ground collision avoidance system in fighter aircraft operations. Int J Aerospace Psychol 29(1-2):28-41. https://doi.org/10.1080/24721840. 2019.1596745

Rogers RO, Boquet A, Howell C, DeJohn C (2010) A two-group experiment to measure simulator-based upset recovery training transfer. Int J Appl Aviation Studies 10(1):153-168

Sagnier C, Loup-Escande E, Lourdeaux D, Thouvenin I, Valléry G (2020) User acceptance of virtual reality: An extended technology acceptance model. Int J Human-Comput Interaction 36(11):9931007. https://doi.org/10.1080/10447318.2019.1708612 
Shen C, Ho J, Ly PTM, Kuo T (2018) Behavioral intentions of using virtual reality in learning: Perspectives of acceptance of information technology and learning style. Virtual Reality. https://doi.org/ 10.1007/s10055-018-0348-1

Sitzmann T (2011) A meta-analytic examination of the instructional effectiveness of computer-based simulation games. Pers Psychol 64(2):489-528. https://doi.org/10.1111/j.1744-6570.2011.01190.x

Soper DS (2020) A-priori sample size calculator for structural equation models [Software]. Available from http://www.danielsoper. $\mathrm{com} /$ statcalc

Smith JW, and Salmon JL (2017) Development and analysis of virtual reality technician-training platform and methods. Proceedings of the Interservice/Industry Training, Simulation, and Education Conference (I/ITSEC) 2017, Orlando, FL.

Suh A, Prophet J (2018) The state of immersive technology research: A literature analysis. Comput Hum Behav 86:77-90. https://doi. org/10.1016/j.chb.2018.04.019

Taylor HL, Talleur DA, Rantanen EM, and Emanuel TW, Jr. (2004) The effectiveness of a personal computer aviation training device (PCATD), a flight training device (FTD), and an airplane in conducting instrument proficiency checks. Final Technical Report AHFD-04-12/FAA-04-05. Oklahoma City, OK: Federal Aviation Administration Civil Aerospace Medical Institute. Retrieved from http://www.tc.faa.gov/logistics/grants/pdf/2001/01-G-037\%20Vol ume\%201.pdf

Taylor HL, Talleur DA, Emanuel TW, and Rantanen EM (2005) Transfer of training effectiveness of a flight training device (FTD). International Symposium on Aviation Psychology, 736-740.
Venkatesh V (2000) Determinants of perceived ease of use: Integrating control, intrinsic motivation, and emotion into the technology acceptance model. Inf Syst Res 11(4):342-365

Virtual Reality Society. (2017). What is virtual reality? Retrieved from Virtual Reality Society: https://www.vrs.org.uk/virtual-reality/ what-is-virtual-reality.html

Wang Y, Anne A, and Ropp T (2016) Applying the technology acceptance model to understand aviation students' perceptions toward augmented reality maintenance training instruction. International Journal of Aviation, Aeronautics, and Aerospace, https://doi.org/ 10.15394/ijaaa.2016.1144

Westland JC (2010) Lower bounds on sample size in structural equation modeling. Electron Commer Res Appl 9(6):476-487. https://doi. org/10.1016/j.elerap.2010.07.003

Women In Aviation. (n.d.). Conversion rate from student pilot. Retrieved from https://womenofaviationweek.org/wp-content/ uploads/pdf/Conversion_rate_student_pilot_table.pdf

Yang Y, Liu Y, Li H, Yu B (2015) Understanding perceived risks in mobile payment acceptance. Ind Manag Data Syst 115(2):253269. https://doi.org/10.1108/IMDS-08-2014-0243

Zaal PM, Schroeder JA, Chung WW (2015) Transfer of training on the vertical motion simulator. J Aircr 52(6):1971-1984. https://doi. org/10.2514/6.2014-2206

Publisher's Note Springer Nature remains neutral with regard to jurisdictional claims in published maps and institutional affiliations. 